\title{
Pemberdayaan Masyarakat Loano Di Masa Pandemi Covid-19
}

\author{
Noor Fitri ${ }^{* 1}$, Tuti Purwaningsih ${ }^{2}$ \\ ${ }^{1}$ Program Studi Kimia, Fakultas Matematika dan Ilmu Pengetahuan Alam, \\ Universitas Islam Indonesia, Yogyakarta \\ ${ }_{2}^{2}$ Program Studi Statistika, Fakultas Matematika dan Ilmu Pengetahuan Alam, \\ Universitas Islam Indonesia, Yogyakarta \\ *Corresponding Email: noor.fitri@uii.ac.id
}

\begin{abstract}
ABSTRAK
Desa Loano merupakan daerah strategis antara bandara Yogyakarta Internasional Airport (YIA) dan Candi Borobudur. Potensi pariwisata dan souvenir Desa Loano sangat besar. Souvenir yang bisa dikembangkan antara lain produk berbasis minyak atsiri. Saat ini, sebagian besar masyarakat Desa Loano adalah petani konvensional. Masyarakat Loano belum memiliki kesadaran yang tinggi akan potensi tanaman atsiri di sekitar mereka yang dapat diolah menjadi minyak atsiri yang mempunyai nilai jual lebih tinggi. Selain itu minyak atsiri tersebut dapat digunakan untuk membuat produk berbasis minyak atsiri seperti sabun cair cuci tangan, sabun cuci piring, handsanitizer, diffuser aroma terapi, lilin aroma terapi. Permasalahan tersebut diakibatkan tingkat kesadaran dan pengetahuan masyarakat masih rendah, disamping itu tidak adanya penyuluh dan pendamping tentang pengembangan potensi pertanian yang ada. Berdasarkan permasalahan tersebut, perlu dilakukan program pemberdayaan masyarakat Desa Loano untuk meningkatkan ekonomi dan kesejahteraannya dengan program KKN-PPM. Solusi yang diterapkan yaitu: (1) Pengolahan bahan baku rempah menjadi produk minyak atsiri; (2) Pembuatan produk turunan berbasis minyak atsiri; (3) Pendampingan manajemen usaha produk berbasis minyak atsiri; serta (4) Pengadaan teknologi tepat guna. Kegiatan KKN PPM yang telah dilakukan berhasil meningkatkan skill masyarakat Loano dan menghasilkan produk berbasis minyak atsiri. Produk berbasis minyak atsiri dapat menjadi salat satu program BUMDES untuk meningkatkan kesejahteraan masyarakat.
\end{abstract}

Kata Kunci: Desa Loano, Kabupaten Purworejo, atsiri, produk souvenir berbasis atsiri

\section{ABSTRACT}

Loano Village is a strategic area between Yogyakarta International Airport (YIA) and Borobudur Temple. The potential for tourism and souvenirs in Loano Village is very large. Souvenirs that can be developed include essential oil-based products. Currently, most of the people of Loano Village are conventional farmers. The Loano community does not yet have a high awareness of the potential of essential plants around them that can be processed into essential oils that have a higher selling value. In addition, these essential oils can be used to make essential oil-based products such as liquid hand soap, dish soap, hand sanitizer, aromatherapy diffuser, aromatherapy candles. It is necessary to carry out an empowerment program for the Loano Village community to improve their economy and welfare with the KKN-PPM program. The solutions applied are: (1) Processing of spice raw materials into essential oil products; (2) Manufacture of essential oil-based derivative products; (3) Assistance in business management of essential oil-based products; and (4) Procurement of appropriate technology. The KKN PPM activities that have been carried out have succeeded in increasing the skills of the Loano community and producing essential oil-based products. Essential oil-based products can be one of the BUMDES programs to improve people's welfare.

Keywords: essential oil-based souvenir products, Loano Village, Purworejo District. 


\section{PENDAHULUAN}

Desa Loano adalah desa yang terletak di Kecamatan Loano, waktu tempuh perjalanan sekitar 20-30 menit dari pusat kota purworejo yang berjarak sekitar 8,9 km dan sekitar 59 menit dari Bandara New Yogyakarta Internasional Airport. Desa Loano terdiri dari 4 dusun dengan luas 285,2 Ha (Pemerintah Desa Loano, 2021). Perangkatnya terdiri dari Seorang Kepala Desa (Kades), satu orang Sekretaris Desa (Sekdes), lima orang kaur dan empat orang Kepala Dusun (Kadus). Jumlah penduduk 917 orang yang terdiri dari 475 orang laki-laki dan 442 orang perempuan, dan dengan jumlah Rumah Tangga Miskin (RTM) 83 RTM. Secara letak topografis tanahnya dataran rendah, dengan lahan sebagian besar dimanfaatkan oleh masyarakat untuk lahan pertanian dan perkebunan sehingga sebagian besar masyarakat desa adalah petani (Pemerintah Desa Loano, 2021).

Hasil pertanian dari Desa Loano adalah padi, umbi-umbian, jagung, kedelai, tanaman kacangkangan, tanaman tradisional rempah-rempah, jeruk, dan tanaman obat seperti kapulaga, temu ireng, temulawak, dan lempuyang. Potensi tanaman di Desa Loano dapat dilihat dalam Tabel 1.

Tabel 1. Potensi Tanaman di Desa Loano

\begin{tabular}{ll}
\hline \multicolumn{1}{c}{ Jenis Tanaman } & \multicolumn{1}{c}{ Lokasi Dusun } \\
\hline Padi & Dusun Krandegan \\
Buah jeruk & Dusun Kalisemo \\
Bambu & Dusun Beru Manis \\
Kencur, Jeruk Nipis & Dusun Beru Tengah \\
\hline
\end{tabular}

Selain memiliki potensi pertanian yang melimpah, Desa Loano juga memiliki potensi perkebunan dan wisata alam seperti kebun jeruk, sungai dan pemancingan ikan. Potensi ini merupakan daya tarik Desa Loano untuk perkembangan kedepannya. Hasil tani desa Loano biasanya dijual langsung ke pengepul, belum ditingkatkan menjadi usaha skala desa. Potensi desa tersebut sebenarnya dapat diolah sehingga dapat meningkatkan taraf hidup penduduk Loano. Salah satu usaha yang dapat dilakukan adalah pemanfaatan tanaman atsiri menjadi minyak atsiri dan produk turunannya. Selama ini agroindustri minyak atsiri di Indonesia masih terbatas pada wilayah tertentu saja, seperti Aceh, Jawa Barat, maupun Sulawesi, padahal hampir di setiap wilayah Indonesia memiliki tanaman atsiri. Selain itu, masalah lain dalam agroindustry minyak atsiri adalah inkontinuitas produksi, kemampuan/skill masyarakat yang belum profesional dan masih menggunakan peralatan yang sederhana, dan belum dikembangkannya produk turunan berbasis atsiri (Fitri dkk., 2015).

Dari hasil survei dan observasi di lapangan, ditemukan beberapa permasalahan untuk mengembangkan potensi produk berbasis minyak atsiri di Loano. Permasalahan tersebut antara lain: (i) masyarakat belum memiliki kesadaran yang tinggi akan potensi yang ada di sekitar lingkungan mereka; (ii) potensi tanaman atsiri yang ada selama ini belum diarahkan dan dikembangkan menjadi minyak atsiri dan produk turunannya; (iii) masyarakat Loano belum memiliki pengetahuan mengenai cara produksi souvenir berbasis minyak atsiri; (iv) alat-alat atau fasilitas pendukung untuk pengolahan bahan baku belum ada.

Berdasarkan permasalahan tersebut maka masyarakat Loano perlu diberdayakan supaya dapat mengolah potensi yang ada menuju peningkatan ekonomi warga. Solusi yang diterapkan dalam mengatasi permasalahan tersebut dapat dilakukan dengan mengadakan pelatihan, pendampingan dan evaluasi. Transfer teknologi penyulingan minyak atsiri tidaklah mudah karena mayoritas masyarakat mempunyai latar belakang pendidikan yang rendah dan pengetahuan yang kurang. Selain itu, adanya masa pandemi covid-19 menyebabkan adanya kendala dalam transfer teknologi kepada warga secara langsung. Oleh karena itu, dilakukan strategi pelatihan yang baik dan mudah dipahami oleh masyarakat awam dengan membuat video pemberdayaan masyarakat. 


\section{METODE}

Pemberdayaan ini merupakan kolaborasi dari tiga pihak. Pihak pertama adalah Universitas Islam Indonesia sebagai pemrakarsa dan pelaksana program, pihak kedua adalah DRPM Dikti yang berperan sebagai penyandang dana; dan pihak ketiga adalah Pemerintah Desa Loano sebagai pemilik otoritas wilayah. Kegiatan KKN-PPM dilakukan secara daring dan luring. Kegiatan KKN-PPM yang dilakukan secara luring adalah: (1) pelatihan TOT mahasiswa KKN berupa pelatihan penggunaan alat destilasi dan pembuatan produk berbasis atsiri (Fitri dkk., 2020; Ramdhan dkk., 2020; Sary dkk., 2020); (2) sosialisasi kegiatan KKN dan penyerahan alat TTG destilasi minyak atsiri dan produk turunannya, (3) pelatihan penggunaan alat TTG destilasi minyak atsiri, dan (4) pembuatan video profil desa Loano dan video kegiatan KKN-PPM. Adapun kegiatan KKN-PPM yang dilakukan secara daring adalah: (1) koordinasi kegiatan KKN-PPM dengan pemerintah desa Loano; (2) pembekalan dan pelatihan mahasiswa KKN-PPM; (3) pelatihan penggunaan alat destilasi oleh mahasiswa KKN kepada masyarakat Loano; (4) video pemberdayaan pelatihan pembuatan produk berbasis atsiri.

\section{PELAKSANAAN DAN PEMBAHASAN}

Desa Loano menjadi salah satu desa untuk pelaksanaan KKN-UII. Desa Loano, mayoritas penduduknya merupakan petani sehingga perekonomian tergerak dari bidang pertanian. Rempahrempah/empon-empon merupakan salah satu dari hasil panen yang berpotensi untuk dikembangkan di Loano. Kondisi alam yang mendukung menyebabkan rempah- rempah seperti kapulaga, kemukus, temulawak, kencur, kunyit, dan jahe tumbuh subur di Loano. Rempah-rempah tersebut berpotensi sebagai peluang usaha. Dengan demikian, pengembangan tanaman tradisional yang paling efektif adalah pemberdayaan masyarakat dengan memanfaatkan tanaman atsiri menjadi minyak atsiri dan produk turunannya.

Strategi yang baik mulai dari pengolahan bahan baku menjadi minyak atsiri dan produk turunannya, penggunaan dan pemeliharaan alat yang benar, serta manajemen bisnis dan pemasaran yang tepat perlu dilakukan untuk optimalisasi potensi rempah Loano. Setiap Langkah strategi pemberdayaan masyarakat dalam hal memanfaatkan tanaman atsiri dibimbing oleh mahasiswa yang berkompeten di bidang ilmunya masing-masing. Mahasiswa kimia membimbing proses ekstraksi tanaman atsiri menjadi minyak atsiri; mahasiswa kimia dan farmasi melatih cara membuat produk turunan berbasis atsiri; Mahasiswa jurusan teknik mesin mempersiapkan perlengkapan alat-alat produksi; mahasiswa jurusan ekonomi dan informatik melakukan penyuluhan starategi bisnis dan pemasaran melalui media sosial. Produk berbasis minyak atsiri yang dibuat oleh mahasiswa di bawah supervise Pembimbing KKN ditampilkan pada Gambar 1. Berbagai macam produk berbasis minyak atsiri telah dibuat, seperti hand sanitizer, hand soap, aromaterapi, lilin aromaterapi, dan minuman aromaterapi. Produk unggulan selain hand sanitizer, adalah sabun cuci tangan (Ramdhan dkk., 2020). Berdasarkan penelitian, penjualan sabun cuci tangan meroket selama masa pandemi (Ahuja \& Mamtani, 2021). 




(a)

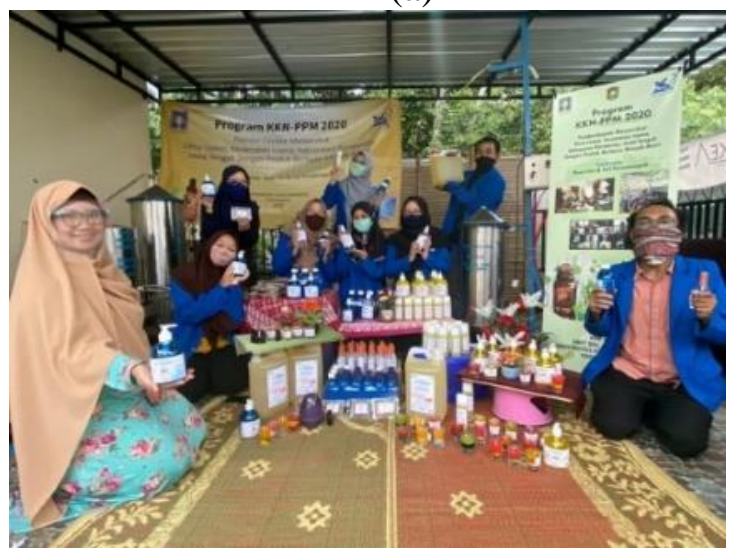

(c)

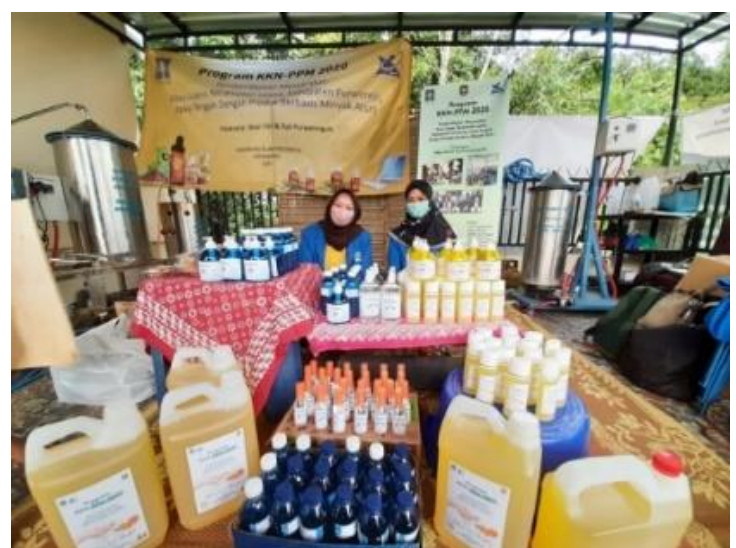

(b)

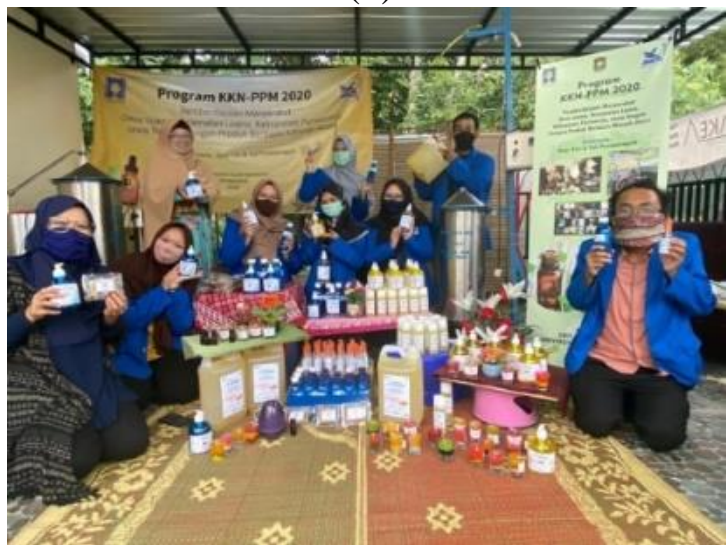

(d)

Gambar 1. Produk KKN-PPM UII berbasis atsiri

\section{Penyerahan Alat Teknologi Tepat Guna Ketel Destilasi dan Produk berbasis minyak atsiri kepada Masyarakat Loano}

Pada hari Selasa, tanggal 11 Agustus 2020 diserahkan alat teknologi tepat guna Ketel destilasi dan produk berbasis minyak atsiri kepada Masyarakat Loano. Selama masa pandemi, kegiatan ini dilakukan dengan protokol covid-19 dan peserta yang mengikuti dibatasi. Mahasiswa yang ikut dalam kegiatan ini hanya 8 orang, perwakilan dari 32 orang mahasiswa KKN. Pada kegiatan ini, pihak UII menyerahkan 2 alat TTG destilasi minyak atsiri, satu alat untuk destilasi air dan uap-air dan 1 alat untuk 3 teknik destilasi, yaitu air, air-uap, dan steam. Selain itu, ratusan produk berbasis atsiri yang telah dibuat oleh mahasiswa KKN juga diserahkan kepada masyarakat Loano. Testimoni masyarakat Loano sangat senang dan baru menyadari bahwa produk yang selama ini dibeli, bisa diproduksi sendiri. Gambar 2 menampilkan foto kegiatan penyerahan alat destilasi serta produk berbasis atsiri. 


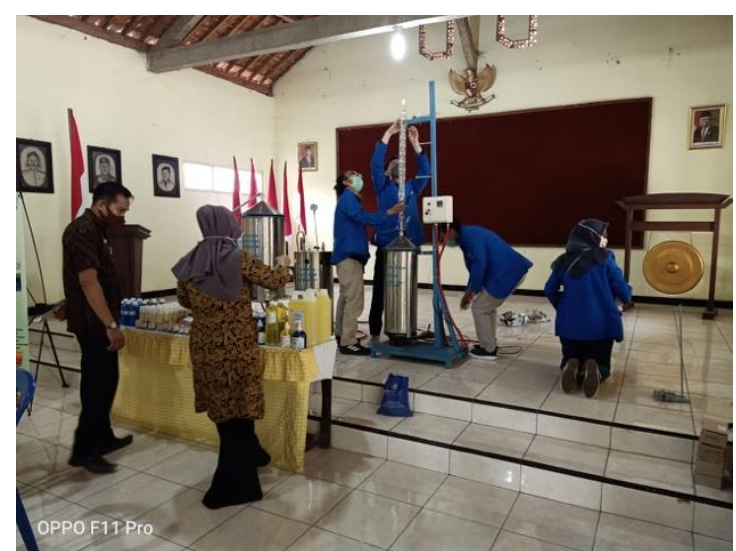

(a)

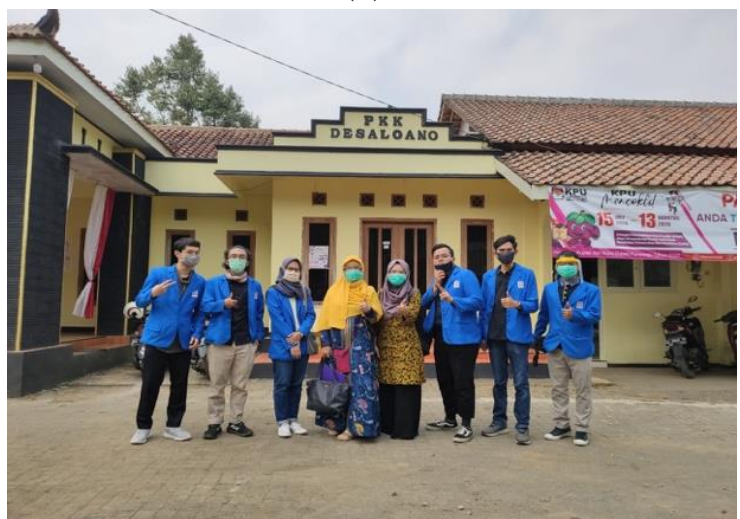

(c)

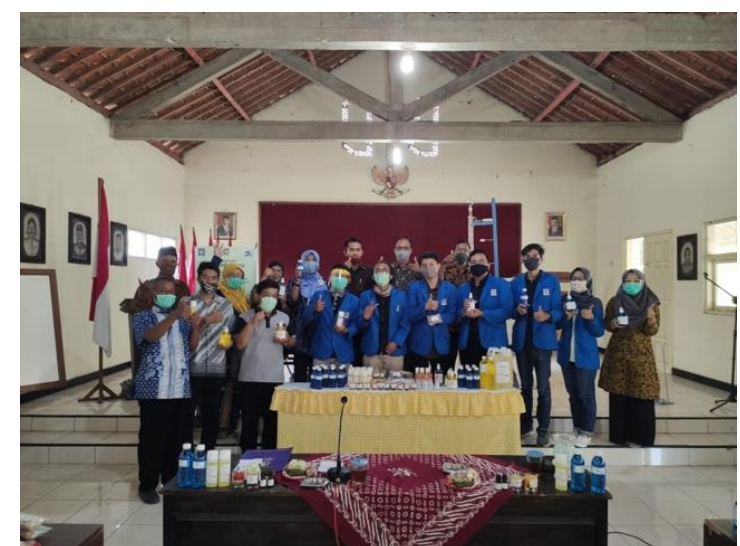

(b)

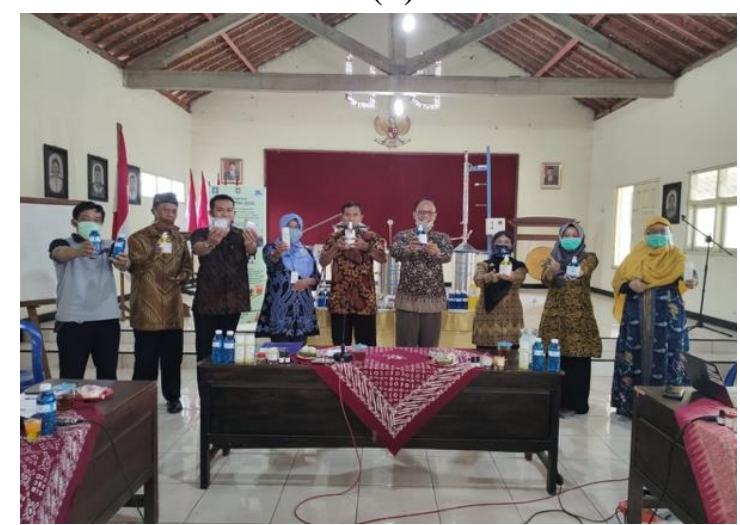

(d)

Gambar 2. Sosialisasi dan Penyerahan Alat TTG serta Produk ke Desa Loano

\section{Pemberdayaan masyarakat Loano membuat produk berbasis minyak atsiri menggunakan video tutorial.}

Selama masa pandemi, kontak langsung mahasiswa KKN dengan masyarakat desa Loano dibatasi. Sehingga Sebagian besar kegiatan KKN dilakukan secara daring. Kegiatan sosialisasi dan pelatihan teknologi tepat guna (TTG) alat destilasi dilakukan secara luring dengan protocol covid. Kegiatan pelatihan TTG penggunaan alat destilasi langsung ketemu masyarakat, karena dikhawatirkan transfer teknologi tersebut akan sulit dipahami jika hanya berupa video kegiatan. Untuk memudahkan proses transfer ilmu dan skill kepada masyarakat, maka luaran kegiatan KKN PPM adalah pembuatan video, yang meliputi (1) Video Pemberdayaan masyarakat; (2) Video Pendidikan untuk siswa SD kelas VI; dan (3) Video Dakwah Islamiah. Video kegiatan ini diupload di channel youtube DPPM UII, dengan harapan materi pemberdayaan tersebut tidak hanya bermanfaat bagi masyarakat Loano, tetapi juga bagi masyarakat umum.

\section{Pelatihan TTG destilasi minyak atsiri dan pembuatan produk berbasis minyak atsiri}

Kegiatan pelatihan TTG penyulingan minyak atsiri dan pembuatan produk berbasis minyak atsiri dilakukan di balai desa Loano pada tanggal 22 Agustus 2020. Kegiatan ini berlangsung seharian dari pagi hingga sore hari dengan menerapkan protocol covid. Umumnya proses preparasi bahan baku yang akan disuling berlangsung 1-2 jam tergantung dari jumlah bahan baku yang akan didestilasi. Kegiatan penyulingan sendiri dapat berlangsung selama 5-6 jam. Air yang ikut menguap Bersama minyak atsiri disebut hydrosol dan beraroma sangat wangi, sehingga dapat digunakan sebagai air destilat untuk pembuatan sanitizer. Foto kegiatan pelatihan TTG destilasi minyak atsiri dapat dilihat pada Gambar 3. 

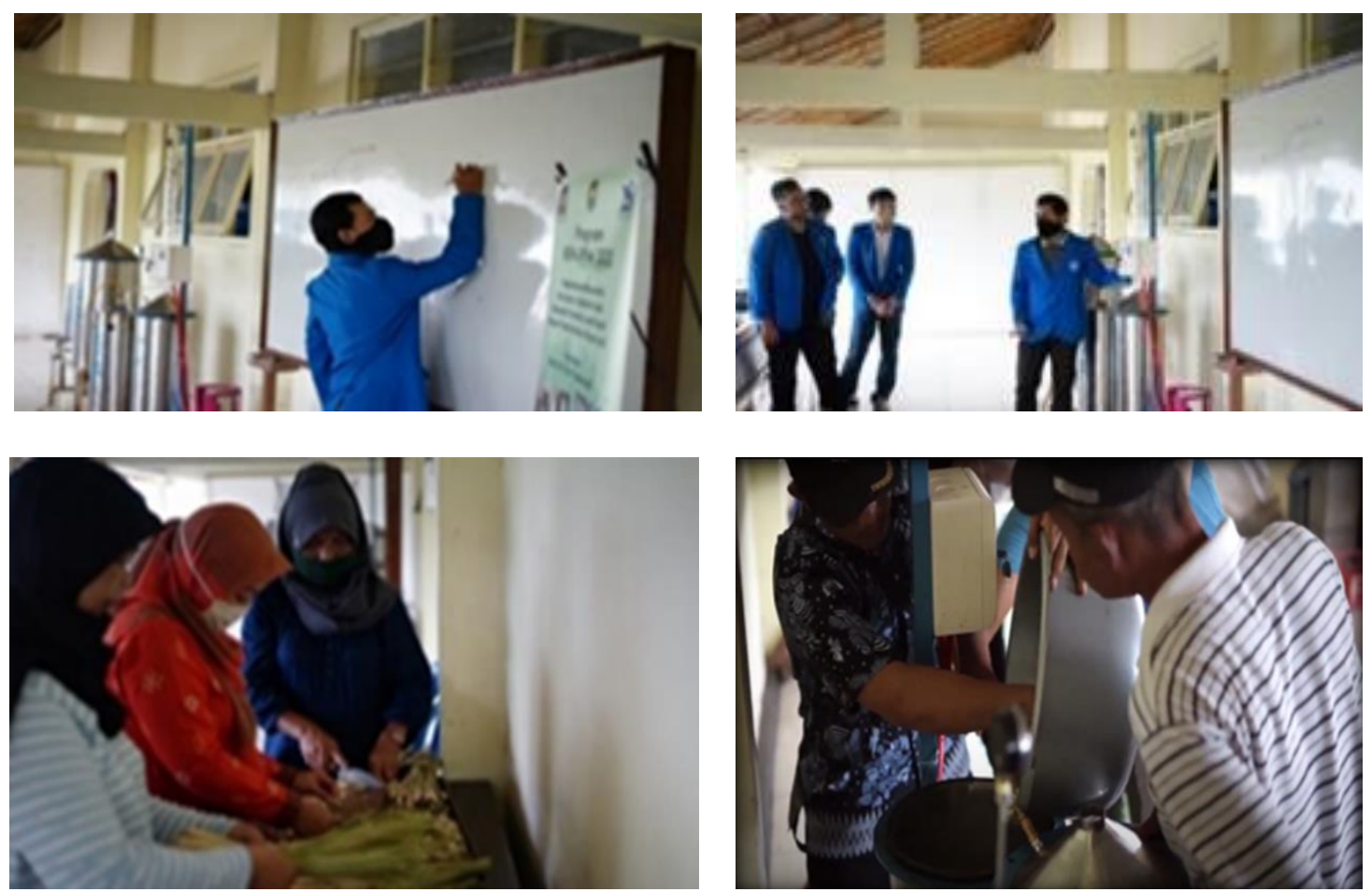

Gambar 3. Pelatihan teknologi tepat guna destilasi minyak atsiri kepada masyarakat Loano

Hambatan utama dalam proses penyulingan, masyarakat belum berani untuk bongkar pasang alat. Sehingga perlu dilakukan pelatihan serupa untuk menyegaran cara dan proses destilasi minyak atsiri. Prinsip utamanya seperti mengukus nasi, hanya saja uap yang keluar dikondensasikan dan ditampung. Dengan penjelasan yang sederhana, diharapkan masyarakat dapat memahami dan praktek langsung menggunakan alat destilasi.

\section{Testimoni Perangkat desa Loano dan masyarakat Loano serta masyarakat umum tentang produk KKN PPM UII berbasis minyak atsiri.}

Perangkat desa Loano dan masyarakat Loano menyambut baik program KKN PPM ini. Hal ini dibuktikan dengan testimoni yang diberikan oleh masyarakat Loano tentang kegiatan dan produk berbasis minyak atsiri yang diberikan. Masyarakat menyambut positif kegiatan pemberdayaan produksi produk berbasis minyak atsiri. Pengetahuan dan skill masyarakat meningkat dan diharapkan dapat menjadi sumber pendapatan tambahan. Masyarakat juga berharap, diselenggarakan pelatihan luring dalam pembuatan berbagai produk berbasis minyak atsiri agar lebih mantap dalam membuat produk. Selama masa pandemi hanya produk Sanitizer yang diajarkan secara luring. Produk sanitizer merupakan produk unggulan tim KKN PPM, karena dibuat dengan mengikuti referensi WHO dengan modifikasi aditif minyak atsiri (Fitri dkk., 2020; Singh dkk., 2020; Suchomel dkk., 2020). Produk sanitizer ini sangat disukai oleh masyarakat karena memiliki wangi yang natural sereh wangi dan tidak ada kesan bau bahan kimia seperti kebanyakan produk sanitizer yang dijual. Masyarakat juga mengusulkan adanya lomba kreativitas membuat lilin aromaterapi sebagai salah satu kegiatan karang taruna di Loano.

\section{SIMPULAN}

Kegiatan KKN PPM telah berjalan dengan lancar dan sukses. Masyarakat Desa Loano Kecematan Loano, Purworejo menyambut baik adanya program hibah KKN-PPM Pemberdayaan Masyarakat melalui optimalisasi pengolahan tanaman atsiri menjadi minyak atsiri dan produk turunannya. Kegiatan ini inline dengan program pemerintah Kabupaten Purworejo yaitu Program Badan Usaha Milik Desa (Bumdes). Produksi Minyak Atsiri dan produk turunannya dapat menjadi salah satu Program unggulan Bumdes desa Loano. Pusat Pengabdian kepada Masyarakat UII berkomitmen untuk mendampingi kegiatan pemberdayaan masyarakat loano sehingga kegiatan 
produksi minyak atsiri dan produk berbasis minyak atsiri dapat berkelanjutan dan signifikan meningkatkan taraf hidup masyarakat Loano.

Kegiatan pemberdayaan masyarakat Loano akan dilanjutkan dengan pendampingan produksi massal souvenir berbasis minyak atsiri dan pengujian produk di Laboratorium Kimia UII untuk menguji kualitasnya. Selain itu pendampingan pemasaran digital produk berbasis minyak atsiri juga akan dilakukan.

\section{UCAPAN TERIMA KASIH}

Penulis mengucapkan terima kasih kepada Direktorat Riset dan Pengabdian Masyarakat, Direktorat Jenderal Penguatan Riset dan Pengembangan, Kementrian Riset, Teknologi, dan Pendidikan Tinggi atas dana hibah yang diberikan sesuai dengan Perjanjian Penugasan Pelaksanaan Program Pengabdian Masyarakat Nomor: 102/SP2H/PPM/DRPM/2020, tanggal 26 Februari 2020. Terima kasih juga dihaturkan kepada Pusat KKN, DPPM UII atas kerjasamanya sehingga kegiatan KKN ini dapat berjalan dengan baik.

\section{DAFTAR PUSTAKA}

Ahuja, K., \& Mamtani, K. (2021). Global liquid hand soap market. Diakses dari https://www.gminsights.com/industry-analysis/global-liquid-hand-soap-market pada tanggal Mei 2021.

Fitri, N., \& Mohammad, D. (2015). Pengembangan Model Techno-Industrial Cluster Minyak Atsiri. Asian Journal of Innovation and Enterpreneurship, 4(03), 181-190.

Fitri, N., Purwaningsih, T., Firdaus, A. F. A., Purnika, D., Kustiawan, R. L., Ardisetya, S., \& Triwening, N. S. R. (2020). Hand sanitizer berbbasis minyak atsiri untuk mengembangkan Desa Loano, Kecamatan Loano, Kabupaten Purworejo, Jawa Tengah sebagai sentra produk berbasis minyak atsiri. Prosiding Seminar Nasional Hasil Penelitian dan Pengabdian Masyarakat "Kesehatan Modern dan Tradisional", 372-384.

Pemerintah Desa Loano. (2021). Profil Desa Loano. Diakses dari https://desaloano.com/ pada Januari 2021

Ramdhan, F., Qodry, L. N., Hanindyta, L. P., Fitri, N., \& Purwaningsih, T. (2020). Penyuluhan dan Pelatihan Pembuatan Sabun Cuci Tangan berbasis minyak atsiri kulit jeruk nipis di Desa Loano, Kecamatan Loano, Kabupaten Purworejo, Jawa Tengah sebagai sentra produk berbasis minyak atsiri. Prosiding Seminar Nasional Hasil Penelitian dan Pengabdian Masyarakat "Kesehatan Modern dan Tradisional", 325-336.

Sary, N., Mulyani, D., Widiastuti, S., Yusuf, A., Wibowo, T. P., Purwaningsih, T., \& Fitri, N. (2020). Pengembangan Produk Sabun cair cuci piring berbasis minyak atsiri kulit jeruk nipis guna meningkatkan perekonomian masyarakat Desa Loano, Kecamatan Loano, Kabupaten Purworejo. Prosiding Seminar Nasional Hasil Penelitian dan Pengabdian Masyarakat "Kesehatan Modern dan Tradisional", 939-401.

Singh, P., Potlia, I., Malhotra, S., Dubey, H., \& Chauhan, C. (2020). Hand Sanitizer an alternative to hand washing- a review of Literature. Journal of Advanced Oral Research 11(2), 137142 .

Suchomel, M., Steinmann, J., \& Kampf, G. (2020). Efficacies of the original and modified World Health Organization-recommended hand-rub formulations. J Hosp Infect 106(2), 264-270. 